\title{
The origin and development of the technical efficiency analysis in the economy from an environmental viewpoint
}

\author{
Jesús Lucindo and Marisa Feijóo* \\ Universidad de Zaragoza
}

Received: 04-03-2020; Accepted: 13-06-2020; Published: 06-07-2020

\begin{abstract}
Objective: Determine the technically efficient behavior for any agent in the economy, being responsible for its environmental performance.

Methodology: Review of the state of the art of the literature on the analysis of technical efficiency from an environmental perspective.

Results: Determine a behavior for an economy and ecological efficiency in order to assume a sustainable development.

Limitations: Given the theoretical modelling developed, the main drawbacks are: the non-presence in the predictive models of the cost of the environmental impact, the lack of tools to collect adequately those impacts that are delayed in time and, finally, the limitations to investigate the influence of the uncontrollable natural factors.

Practical implications: Action guides for individuals, firms and states to meet their needs with the least impact on the environment. Special attention to supply to decision-makers with an adequate study for the proper design of environmental regulations.
\end{abstract}

Keywords: efficiency; production; environmental; sustainable development.

JEL codes: D24, Q59.

Lucindo Blasco, J., \& Feijóo, M., 2020, The origin and development of the technical efficiency analysis in the economy from an environmental viewpoint, Esic Market Economics and Business Journal, 51(2), 385-410. Doi: 10.7200/esicm.166.0512.4

\footnotetext{
" Corresponding author. Email:
}

ISSN 0212-1867 / e-ISSN 1989-3574

(C) ESIC Editorial, ESIC Business \& Marketing School

DOI: $10.7200 /$ esicm.166.0512.4

http://www.esic.edu/esicmarket 


\section{从环保角度对经济中技术效率分析的起源与 发展}

Jesús Lucindo and Marisa Feijóo

Universidad de Zaragoza

\section{文章摘要}

研究目的：为对环境负责的人士或组织确定有效益的行为。

分析方法：从环境角度回顾过往有关对技术效率进行的分析的文献现况。

研究结论：以实现可持续发展为目的, 确定有利于经济和生态的行为。

研究局限: 鉴于已开发的理论模型, 现时主要的缺点是：总体来说缺乏能预测 环境影响成本的模型, 同时也缺乏足够工具以充分收集那些延迟出现的影响。 最后是, 由于研究过程受到无法控制的自然因素影响而有所限制。

实际应用: 研究结果可以作为对个人、企业以及各国的指南, 以对环境造成最少 影响的情况下满足其需求, 尤其是为决策提供方针, 从适当的研究得出结论来 有效制定有关环保的法规。

关键词：效率、生产、环境、可持续发展。

JEL 分类号: D24、Q59。

\footnotetext{
" Corresponding author. Email:
}

ISSN 0212-1867 / e-ISSN 1989-3574

(C) ESIC Editorial, ESIC Business \& Marketing School

DOI: $10.7200 /$ esicm.166.0512.4

http://www.esic.edu/esicmarket 


\section{Introduction}

The environmental and the sustainable development is one of the most important topics of intellectual discussion due to the great involvement in the development of our socio-economic model. The concept of sustainability, according to the World Commission on Environment and Development of the United Nations (UN), is understood as the ability of current generations to meet their needs without compromising the ability of future generations to meet their own needs. This capacity contains, very closely related to each other, concepts such as economic, social, environmental, technological, etc. However, a common characteristic is shared by all of them: Scarcity, the availability and the use of each of them is limited.

To answer the problem of scarcity, the economy long time ago thanks to the approaches of the Neoclassical School of the late nineteenth century and the early twentieth century, it conceptualized novel ideas around the partial and the general market equilibrium, the welfare economics, the economic cycles, the monetarism, the perfect and the imperfect competition, etc.; all these contributions along with others more recent are still very valid today. Some of the most prominent authors of this School are León Walras (1834 - 1910), Alfred Marshall (1842 - 1924), Francis Edgeworth (1845 - 1926), Vilfredo Pareto (1848 - 1923), Irving Fisher (1867 1947), Arthur Pigou (1877 - 1959), among others.

The birth of the efficiency term in the economy did not come by the approximation of a single concept, but through the mediation of several of them such as the laws of the supply and the demand for the allocation of a market equilibrium, as well as the welfare economy. In this way, the term of efficiency is the relation obtained by the adequate employment of the resources used in comparison with the available alternatives. This term is fundamental in the perception of the own economy as the organization of the use of scare resources to satisfy individual or collective needs where nobody can improve their situation without making someone else worse.

Thereby, traditionally the efficiency analysis carried out by any individual or organization aims to optimize their performance in the long-term ceteris paribus from some simple rules of action. To reach a situation where, first, the wishes are fulfilled and, second, it gets the tools according to their ability to achieve such situation.

An overview, although it is not the subject of this article, the existent discussion of the modern literature about the traditional view of the efficiency in the economy and the non-inclusion of relevant aspects such as, the asymmetry in the information by the participants (Arkerlof, 1970), the presence of externalities (Baumol, 1972), the difficult existence of perfectly competitive and balanced markets without costs (Grossman \& Stiglitz, 1980), the absence of public regulation in the market (Minsky, 1986 ) and, the social inequality in the market allocation mechanisms (Sen, 1995).

On the one hand, at microeconomic level, the individuals want to utilize adequately the elements to maximize their satisfaction. And on the other hand, at macroeconomic level, the firms want to achieve a productive behavior that gives them a competitive advantage in the market face other rivals and, the states want to design 
public policies that satisfy their citizens with a certain level of spending. One thing is clear, an inadequate analysis of the reality will cause harmful decisions with results obtained far away from proposed objectives. The initial theoretical analysis must be able to keep it in mind all the variables necessary for the subsequent evaluation of the activity performed.

Currently, the threat of ecological deterioration can change everything we know so far, to this threat has not been dedicated all the attention that demands its urgency to act. The degradation of the environment due to the global climate change by the direct human action is the greatest source of uncertainty that the humanity must face in the coming years (Cook et al., 2013). According to the Intergovernmental Panel on Climate Change (IPCC) of United Nations, the accumulation of greenhouse gas emissions (GHG) (carbon dioxide $\mathrm{CO}_{2}$ emissions and, to a lesser extent, methane $\mathrm{CH}_{4}$ and nitrous oxide $\mathrm{N}_{2} \mathrm{O}$ ) caused by human activity throughout the history are bringing about the weakening and the decrease of the ozone layer of the atmosphere of the planet Earth. Nowadays, the $\mathrm{CO}_{2}$ emissions have increased from approximately pre-industrial values from $280 \mathrm{ppm}$ (parts per million) to $379 \mathrm{ppm}$, likewise, the $\mathrm{CH}_{4}$ emissions have made it up to about $1,774 \mathrm{ppb}$ (parts per billion) which represents more than double its pre-industrial value and, lastly, the $\mathrm{N}_{2} \mathrm{O}$ gases of are 319 ppb approximately $18 \%$ higher than its pre-industrial value. Such increases are leading to a climate change whose distortions can be observed in multiple aspects of the environment. Like, for example, the temperature (estimation of an overall increase of approximately $1,0^{\circ} \mathrm{C}$ with respect to pre-industrial levels, with a probable range from $0,8{ }^{\circ} \mathrm{C}$ to $1,2{ }^{\circ} \mathrm{C}$ ), the rainfalls (estimation of episodes of greater intensity in mid-latitude areas and humid tropical regions), the level of the sea (confirmation along of the twentieth century of a global sea level rise of about $15 \mathrm{~cm}$, which continues to accelerate annually), the extreme natural phenomena (high probability of increased intensity of tropical cyclones in the Pacific and the North Atlantic), etc. In accordance with Stocker et al. (2013), the climate change has been unequivocal by the human influence since the 1950s in light of concentrations of the polluting gases in the atmosphere. The continuous emissions will cause new changes in all components of the climate system, unless are substantially and sustainably reduced.

The analysis and the management of the climate change have been recognized as a major economic problem decades ago (Nordhaus, 1977), however, important economic and social issues remain unresolved today (Hsiang \& Kopp, 2018). Among these questions, the integration in the efficiency analysis of the resulting aspects from environmental degradation due to climate change emerges. The traditional analysis presented is no longer valid since the omission of the associated variables with the impact of pollution, it will distort the results to estimate the efficiency. All of this, it will seriously damage subsequent decision-making in individuals, businessmen and policy-makers (Song et al., 2012).

The necessity to take adequate evaluations of the efficiency for making correct decisions is a thing of the most immediate present. To indicate several examples of the multiple empirical analysis carried out, Camarero et al. (2013) develop the 
efficiency analysis, including environmental aspects, and its degree of convergence in 22 OECD (Organisation for Economic Cooperation and Development) countries for the period 1980-2008. They draw three main conclusions. First, there is a growing global trend in the ability of economies to produce more goods and services with less impact on the environment, it motivated by the increasing regulation of carbon dioxide emissions in developed countries. Second, the most environmentally efficient countries are Switzerland, Norway, Sweden and Denmark, on the contrary, the worst are Portugal, Spain, Greek, Hungary, Turkey, Canada and the United States. Third and last, the formation of convergence clusters among countries, in other words, the convergence is taking place, on the one hand, among the countries with the best environmental performance and, on the other hand, among the countries with the worst performance. Every time, the degree of separation between the two clusters is increasing. Also, Sanz-Díaz et al. (2017), analysed the environmental efficiency of Spain during the period 2005-2012 regarding the rest of the twenty-eight member countries of the European Union. The result indicates that Spain's environmental performance is more similar to the Eastern European countries (Czech Republic, Slovakia, Croatia, Slovenia and Hungary), recently joined the Union, that to the surrounding countries. The authors argue that the strong disinvestment in recent years in renewable energies and in cleaner production technologies by the private and public sectors is the main argument for Spain appear in the last position among the enclosing countries in environmental action.

The literature on the measurement of efficiency has been fundamentally supported, thanks to the good marks obtained, in the methodology of frontiers based on parametric or non-parametric techniques. In the first case, it is necessary to specify a functional form with the defined parameters of the efficient frontier and by means of the econometric estimation find the values that make up this frontier. This way, the deviation from the frontier will be given by two possible elements, one that reflects the inefficiency itself and, another that shows the stochastic random term. This method is commonly known as the Stochastic Frontier Analysis (SFA). As a reference, the precursor works of this modeling, Aigner \& Chu (1968); Aigner, Lovell \& Schmidt (1977); and Meeusen \& Den Broeck (1977). In the second case, the efficient frontier will not have a specific functional form and with the mathematical linear programming the values that conform this frontier must be found. The deviation will be deterministic, in the sense that all of it will come from the real inefficiency itself, and under no circumstances will be given by a random term. This last methodology is commonly known as the Data Envelopment Analysis (DEA), it being the most used for research thanks to its flexibility (Emrouznejad et al., 2008), but whose principal drawback is the lack of statistical properties in the results obtained with the mathematical programming (Seiford \& Thrall, 1990; Fried et al., 1999; Fried et al., 2002). As a reference, the precursor works of this modeling, Charnes, Cooper \& Rhodes (1978); Charnes, Cooper \& Rhodes (1981); and Banker, Charnes \& Rhodes (1984).

The objective of this article is to evaluate the state of the art about the analysis of technical efficiency through an economic perspective, from its origins with a limited 
focus on the good use of scarce resources to obtain the best possible results, up to the recent formulations most concerned with incorporating the possible environmental impact to make efficient decisions. The rest of the article is structured as follows. The section 2 reviews the birth and subsequent evolution of technical efficiency from a strictly economic perspective. The section 3 will show, through the most widely used framework in the literature, non-parametric techniques, the estimation of efficiency using the Malmquist index number. Next, the section 4 will include the new approaches to the analysis of efficiency, containing environmental degradation caused by human action. Finally, the conclusions are organised in the section 5 .

\section{The origin of the technical efficiency analysis}

It was Koopmans (1951) by means of the analysis of a firm production, the first author who focused on the technical efficiency, claiming that a feasible combination of factors (inputs) and products (outputs) is technically efficient, given a technology, as long as it is impossible to increase the production of some product or reduce some factor employed without simultaneously reducing at least the production of another product or increasing at least another factor. Inspired by the previous work, Farrell (1957) added a new concept to the technical efficiency, the allocative efficiency, that he denominated the price efficiency. The allocative efficiency consists of choosing, among the technically efficient inputs and outputs combinations, the one that is the cheapest with regard to the prices of the inputs.

A firm that shows price inefficiency is mistakenly using some of its factors, that is, it is not maximizing its product for a given set of factors (technical inefficiency), or it is misusing the combination of factors given the price, rather, it is not employing the factors in the optimal proportion given the price to produce a certain level of product (allocative inefficiency), or both at the same time.

For Leibenstein (1966), the most inefficiencies are rooted in management and / or organizational errors, he claims that its are due, first, a poor election of the production plan (allocative inefficiency) and, second, a bad implementation of the production plan (technical inefficiency).

Figure 1. The origin of the efficiency in the economy

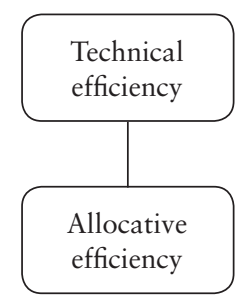

Source: Prepared by the authors. 
The Koopmans and Farrell's technical efficiency measures are inspired by radial proposals, given that they allude to the fact that it measures the maximum equiproportional reduction of all factors with the same production level or, alternately, the greatest equiproportional increase in the production that could obtain using the factors in the same quantity. They contemplate increases of the products or reductions of the factors, but all of them in the same proportion, so they are invariant in the presence of changes in the measurement units.

However, this kind of measures present a major problem, and it is that they do not detect all the possible situations in which there is technical inefficiency, since this may be due to an overuse of certain factors, not all of them. That is, the theory clearly determines which is the efficient standard that compares the economic activity that the firms develop, but in the practice, it is not so easy to estimate the efficient economic behavior functions for each firm. As Seitz (1970) and Afriat (1972) mentioned, the theoretical model developed by Farrell (1957) to the estimation of the efficient production function is applicable to a wide variety of possible behavioral functions.

From the distance functions that only require data about the number of factors and products of the model, Charnes, Cooper \& Rhodes (1978) laid out, by using linear programming techniques, for a set of "Decision Making Unit" (DMU) a selection of the efficient behaviors for every of them, from among all possible, in order to construct an envelope of the efficient observations (efficient frontier). This term refers to the fact that it is not possible to be more efficient than firms located on the border. Therefore, it is possible to estimate the technical efficiency based on the distance that separates the behavior of the DMU with respect to the border. An advantage of such a model is the possibility of reducing a general scenario of the multiple factors and products to a single factor and product, without need to specify a priori functional form or granted weights.

The starting hypothesis for said analysis was constant returns to scale, in other words, when the change in the relation of the production function between factors and products is proportional. This method of estimating the technical efficiency is commonly denominated Data Envelopment Analysis (DEA).

Likewise, Charnes, Cooper \& Rhodes (1981), expanded the DEA framework presented by means of a factor or product orientation. The efficient factor-oriented frontier will be one that represents all possible combinations of factors with the same resulting quantity of production. And the efficient product-oriented frontier will be one that represents all the possible combinations of production with the same amount of factors used. The estimation of the technical efficiency by means of the factor or product orientation will only give the same result when the hypothesis of constant returns to scale is fulfilled. This new representation indicates the non-dependence in the estimation of the technical efficiency of the price level in the data used for the factors and products.

Afterwards, Banker, Charnes \& Rhodes (1984), adopted the technique in the case of a model of variable returns to scale, giving the possibility of a change in the 
estimation of the efficiency come, in turn, by a change simply in the efficiency or, by a change in the scale.

Figure 2. Analysis of the technical efficiency with variable returns to scale with the DEA framework

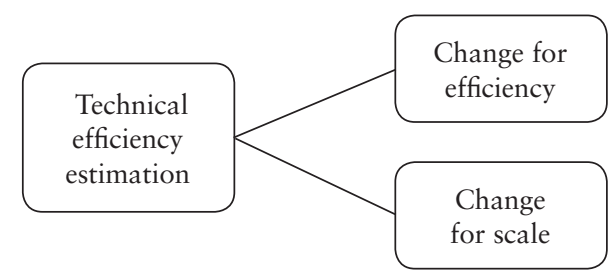

Source: Prepared by the authors.

Banker \& Morey (1985), and Banker \& Morey (1986) demonstrated the adequate operation of the DEA framework in the presence of fixed factors and products, that is, uncontrollable for estimating the efficiency in the behavior of the DMU. In this scenario, the empirical exercise carried out in their works estimate the efficiency through the opportunity in those factors (via savings) and products (via profit from them) controllable only.

A new variant for estimating the technical efficiency was introduced through the use of the efficiency indices. Caves, Christensen \& Diewert (1982) showed that, in the practice, the index numbers, understood as the statistical measure that allows comparing a magnitude in two different situations, they are extremely useful for having the following mathematical properties. First, a value bounded between one and zero, that is, the value one is reached when there is technical efficiency and the zero value implies absolute inefficiency. Second, the result is proportional in front of the reduction or the increase of the quantity of factors or products employed, this is, homogeneity in the production function since it presents a constant to scale multiplicative behavior. And finally, third, both factor-oriented and product-oriented technical efficiency are invariant in the face of changes in their units of measure. Likewise, in a scenario of the constant returns, both numerical indices oriented towards factors or products will coincide, result that will not occur with variable returns. In mentioned article, they used the Törnqvist and the Malmquist indices, although with greater preference for the second of them, given it is a generalization of the former with a greater number of possible implications before more diverse situations.

\section{The Malmquist productivity index}

This index was devised by Malmquist (1953) as an indicator for a production function with a constant technology of a firm that gives the relationship between the 
maximum possible production of a single product with respect to a set of factors. In that case, the technological progress is considered neutral, in the sense that in the long term the production function curve will shift only as a consequence of the technological progress, since it is possible, it obtain a certain level of the production with a smaller number of factors consumed with proportional way.

It will not be until Solow (1957) when a distinction is made between the single-factor (the production measure for a single factor) and the multi-factor (for a set of factors) productivity measure. Also according the neutral technological progress, the production function curve will shift equal to a cumulative effect as a result of the increased production regarding to all factors. Thanks to the previous work, the Malmquist index is expanded to a multi-factor productivity index, also denominated total, which takes into account the aggregate of production and the factors involved in all the single-factor measures, thus it allows to take into account at the same time all the productive factors used.

The problem of measuring productivity arises in fact when a firm produces more than one product using more than one factor, nevertheless, the mathematical theory of the index numbers solves this question as long as the production function is linear, homogeneous and flexible.

The Malmquist index suggest by Caves, Christensen \& Diewert (1982) for use in estimating the technical efficiency lie in calculating indices from the distance functions, therefore it does not require disposable price data or other assessment, but simply it is necessary quantitative data. From the distance functions will be possible evaluate the firm's efficiency degree and, if it is not, the how and the why of this inefficiency in relation to optimal market efficiency for all firms. This index allows to measure the change in efficiency between two periods. An index value greater than one indicates that the efficiency in the subsequent period is greater that of the immediately previous period. To the contrary, a value less than one indicates that the efficiency has decreased between both periods.

The assessment of the Malmquist index by means of the non-parametric techniques and the use of the panel data enabled Färe et al. (1994) go in depth in the possibilities of this index to study the evolution of the efficiency between different agents and periods. On the basis of the assumptions of a strong disposability of factors and products (as defined Kumar 2006, the strong disposability implies that an increase or a reduction is possible without fall into any king of loss, that is, this framework let to increase or decrease these factors and products without need to give up on either; otherwise for the weak disposability) and the constant returns to scale, the assessment of the technical efficiency change originated between two periods can be decomposed, on the one hand, a change by the technology employed and, on the other hand, a change by the own efficiency in the use adequate of the factors. The first shift reflects the innovation in the technology used that modifies the production frontier over time. And the second shift explains a "catch-up" effect whose significance is the adoption of the best production real practises to be able to locate somewhere on the frontier at any time. This way, it can be distinguished that 
there are two possible sources of inefficiency for which it does not reach the efficient frontier, the first case because it does not use the real technology adequately and the second case on the occasion of assigning incorrectly the available factors.

Figure 3. Analysis of the technical efficiency with constant returns to scale through the Malmquist index and the DEA framework

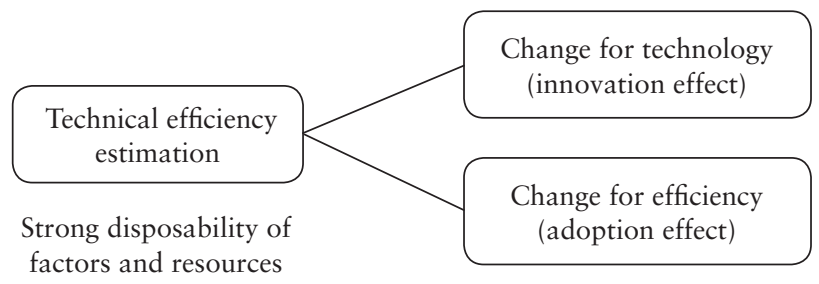

Source: Prepared by the authors.

Afterwards, these authors introduced variable returns to scale, which allowed them to split up again the technical efficiency analysis into three components. Fist, a change in the technology. Second, a pure change in the efficiency for the proper use of factors. And, finally, a change motivated by the variable scale of returns. The first two effects have already been explained previously. The remaining effect is a residual component that will depend exclusively on the non-proportionality between the factors and the products of the model. Later workpapers, such as Grifell-Tatje \& Lovell (1995), have demonstrated the systematic presence of over and underestimation in the analysis of efficiency through the assessment of the Malmquist index about the shift in productivity between two periods in face of decreasing and increasing returns to scale respectively.

Figure 4. Analysis of the technical efficiency with variable returns to scale through the Malmquist index and the DEA framework

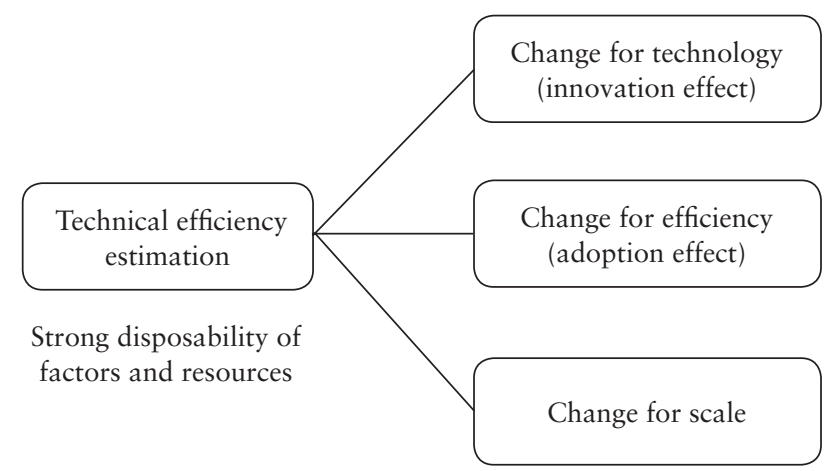

Source: Prepared by the authors. 
As noted in the previous empirical analyzes carried out by the literature, a value of any of the elements into which Malmquist index has been decomposed, greater than one denotes an improvement in efficiency and, therefore, a relevant performance compared to previous periods. To the contrary, a value less than one means a drop in efficiency and a deterioration compared other periods. Each agent in the sample for every time period will have a discrete value to every element used to analyze technical efficiency. A value equal to one implies the best practices of the sample set corresponding to the efficient frontier. As a consequence, the degree of inefficiency will be given by the distance between the result estimated and the frontier, this inefficiency is a by-product or negative result of the estimated model.

Let us remember before of following like the Farrell's (1957) original paper laid down two important requirements in the theoretical framework. The presence of constant returns to scale and the necessity of the strong disposability of the factors and products (Färe \& Lovell, 1972). Grosskopf (1986) indicates that the measures proposed to estimate the efficiency through the non-parametric techniques (mathematical linear programming) will be largely conditioned by the bias generated by the restrictions assumed in the production function's technology due to the existence of the constant or variable returns to scale and, to the strong or weak disposability of the factors.

Coelli \& Rao (2005) have highlighted that the constant returns to scale are the only viable option to assessment the Malmquist index because of the presence of the possible biases when it utilizes aggregate data in a panel of multiple periods and agents. Nevertheless, when it works with cross section data or panel data, Culliname, Ji \& Wang (2005) defend the use of a data panel because it reflects the real efficiency of each agent, given that it let an agent to be compared with others, in addition it let one to measure its performance with respect to different periods.

The traditional assessment of the technical efficiency of the production function without further variables to be defined in the model, as well as the consequent empirical analysis that are provided, it is going to find time and time again the same result: All settled environmental regulations will have an adverse effect on efficiency. These findings ignore the key feature of the environmental regulations which diverts factors into activities to reduce harmful by-products (contamination of any type of the substance or physical element in the nature) generated by the productive activity. The traditional measures only check the non-optimization in the relationship between the disposability of the factors and the generated products. Therefore, the environmental regulation should not aim to decrease the productive activities that cause harmful by-products, in its place, it should aim to directly reduce these harmful products. This mistaken approach of the environmental policy is rooted in a failed theoretical analysis where it omits the undesirable products generated whose prices are not generally available (not the norm, for example, the dioxide carbon $\mathrm{CO}_{2}$ emissions rights trade) (Kumar, 2006). The new methods should measure the technical efficiency of the desirable and undesirable products jointly, the non separability can be interpreted as a more realistic assessment of the effort required by each agent to be efficient (Scheel, 2001). 


\section{Analysis of technical efficiency with environmental performance}

Since Färe \& et al. (1989), the economic literature is aware of the presence of undesirable by-products, just like the necessity to quantify the burden of the regulatory actions on environmental policy that restrict the agent's ability to generate these by-products in their normal productive activity. These authors suggested to develop and establish an evaluation measure applicable to a multi-factor and product model where the agents can produce both desirable and undesirable products. The theoretical framework follows the approaches of Pittman (1983) who was the first author to treat differently the desirable and undesirable products in the analysis. Nevertheless, there are two important differences with respect of the structure proposed by Pittman. First of all, the analysis of Färe et al., formalise a non-parametric linear technology model based on Farrell's article to generate efficiency measures given the asymmetric treatment among factors, desirable and undesirable products. The requirement of the linear technology hypothesis allows them to quantify strong or weak disposability for the undesirable products as a result of the introduction of an environmental regulation by an authority that restricts the total amount of the production. At the beginning, its framework limits the disposability of the undesirable products (since the evidence of an increase or decrease in this kind of products will induce a cost or harm to the agent, that is, given the null union axiom of the distance function model, a reduction of the undesirable products can only accomplish through the reduction of the level of the desirable product). These authors suggest it unreasonable to assume weak disposability for the undesirable products and strong disposability for the desirable products because it would imply that the bad products as a by-product of the good ones could be freely ready without any restrictions or cost. For this reason, it was finally decided to apply the weak disposability for all types of products. Secondly, on the basis of a non-parametric model, Färe et al. only need of the quantity data for the factors and the both types of products. Pittman, on the contrary, employ a parametric framework, it requires the use of a greater number of the data sources, among them to highlight the requirement of the proxy variables that reflect the involved or shadow price of the undesirable products (these prices reflect the impact of the environmental regulation that firms face it, and therefore it can be used to assessment its effectiveness, Färe et al., 1993). Finally, the analysis of the technical efficiency will aim to search for a production function for an agent, given technology, where the maximum possible proportional difference is achieved between the increase of all desirable products and the reduction of all undesirable, in addition to achieve the maximum possible reduction of all production factors. The conclusion acquired in their article suggests a change of the finished efficiency analysis philosophy until now, from this point on, the assessment of the efficiency in firms, industries, countries or any other agent can be very misleading if the undesirable by-products and the degree of regulatory restriction are ignored.

As a result, the most of the recent studies have sought to assess the technical efficiency of the agents, whereas it keep their environmental performance in mind in 
order to show the correct action guidelines (Tyteca, 1996 and 1997). The environmental behavior judges the different impacts of the agents in the nature that originate the so-called undesirable products. To do this, the framework used can be, as it has already been commented previously and in a traditional way in the literature, the parametric or non-parametric models. However, it is confirmed by the claim of recent workpapers, such as the Data Envelopment Analysis (DEA) is the most theoretically ideal approach, although as a last resort, the best judgment will be the researcher's decision to deal with this issue. Yang \& Pollit (2009 and 2010) point out among its advantages, the robustness of linear programming methods, as well as the flexibility to introduce new variables attributable to the environment but which are neither a factor nor a product of the production process. Also the presence of an environmental performance efficient frontier can be seen as an ecological quality objective to be achieved. Zaim (2004) prepared a pollution intensity index by means of the DEA framework and it make use of the distance functions, he tested that this model was perfect to add weights for the individual emissions to estimate the total aggregate pollution intensity. This assessment is endogenous for every agent in the sample, it is being easy to replace it among different indicators of the environmental pressure.

Lozano \& Gutiérrez (2008) highlight that the main elements of environmental degradation are the population, the production and, lastly, the energy consumption (where it stress the percentage of fossil energy consumed and the mix between the different energy sources used for its generation). Along the same line, Du et al. (2017) point out the economic growth as the principal cause of contamination and its direct link with the increases in temperatures in the United States and the European Union. Jeon \& Sickles (2004) indicate a minimal improvement in the efficiency assessment under a framework that includes the environmental cost to study the production growth rate of the all OECD countries for 1980-1990. Also, Meleddu \& Pulina (2018) stand out the public expenditure as a significant determinant of the environmental quality. Since the empirical analysis through the Malmquist index for a data panel of the 21 regions of Italy for the period 2004-2011, they demonstrate how the establishment of expansive public expenditure policies in times of economic recession, it pushes up the environmental efficiency. It is an obvious insight for all the policy-makers to not prioritize a possible rapid economic growth unsustainable environmentally in times of crisis because its negative externalities will return sooner rather later to damage the economy.

There is a debate in the literature about the theoretical structure of the pollution in normal production conditions to model its impact (negative externalities). Apart from this (Dyckhoff \& Allen, 2001), it is the viewpoint to handle the pollution as a formal factor of the production, obviously a factor of negative incidence in the production process. Due to the appearance of costs for the firms (the need to contract environmental purification services) and, so the wish to reduce them as much as possible. That is, these undesirable production factors can be reduced according with its management. On the other hand (Zaim \& Taskin, 2000), it is the perspective 
to regard the pollution as a product caused in the production process with reference to be a weird product, which the attention focused on its minimization. These undesirable products can be reduced only in the same proportion of the decrease in the production level of the desirable product. Nevertheless, this last hypothesis has also generated a great controversy give the requirement about the degree of disposability of the undesirable products (that is, the presence or not of an environmental regulation that limits it somehow).

To sum up of this present debate for the environmental degradation and its modelling as a factor or product, the following figure is a summary of both approaches. One is able to perceive as desirable from an ecological viewpoint, the reduction of the pollution as a productive factor of the process, as well as the normal production of the desirable good. Otherwise, it is ecologically undesirable, the consumption of productive factors extracted from the environment and, the pollution of the final production process as an undesirable product too.

Figure 5. Categorisation of the environmental degradation as a factor or product according to its incidence

\begin{tabular}{cccc}
\hline Position & Goject class & Neutral & Bad \\
\hline Factor (input) & Factor & Reduction \\
\hline Product (output) & Product & Pollution \\
\hline
\end{tabular}

\begin{tabular}{ccc}
\hline & \\
\hline $\begin{array}{c}\text { Ecologically } \\
\text { desirable }\end{array}$ & Indifferent & $\begin{array}{l}\text { Ecologically } \\
\text { undesirable }\end{array}$
\end{tabular}

Source: Dyckhoff \& Allen, 2001.

Hailu (2003) defends the idea that it is possible for an agent to increase desirable products, decrease the undesirable and also decrease the production factors (so, there is a strong disposability of the undesirable products). The reason for this is the coming technological change that may occur, which can be totally unexpected.

It is likely the birth of a cleaner and more efficient technology that allow with less resources to increase the production and decrease pollution.

On the contrary, Färe \& Grosskopf (2003) assume the hypothesis of the weak disposability of the undesirable products by which these products can only be reduced in equal proportion to the decrease in the desirable products since these latter originate the former. The explanation is the physical laws (finite and scarce quantities generate exactly the same, finite and scarce quantities) to show the opportunity cost of the undesirable products. These undesirable ones decrease if some 
factors dedicate to clean up the pollution made. As a result, there are fewer factors to produce desirable products, at the end there are fewer undesirable products too. Kuosmanen (2005) point out this framework implies the assumption that all agents in the sample must make an uniform decrease in the production factors, nevertheless, it is not in line with the literature where the reduction will be only made by those agents with the least potential damage. This author indicates that the weak disposability to reduce the factors as much as the desirable and undesirable production could be theoretical formalized in the presence of the inactive agents in the sample.

Figure 6. Weak and strong disposability of the undesirable products
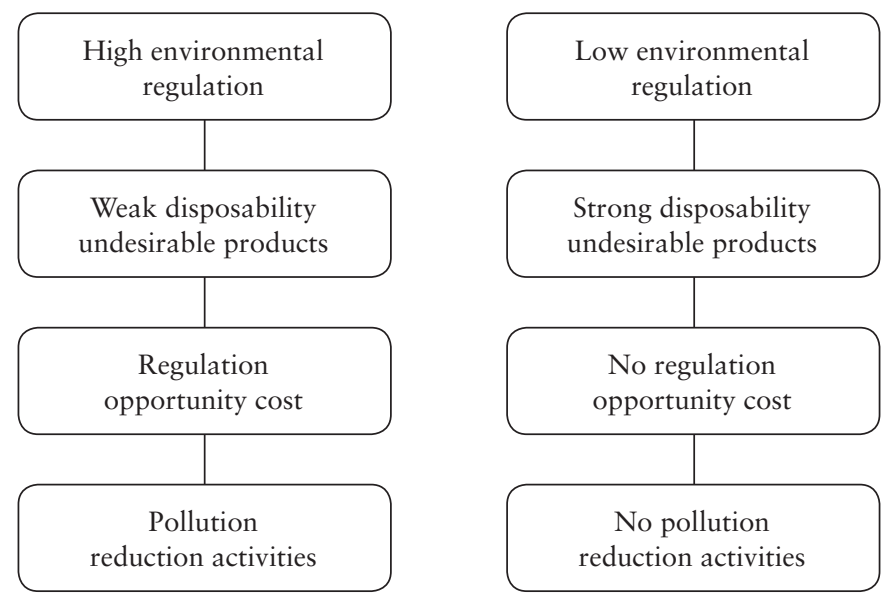

Source: Prepared by the authors.

The estimation of the technical efficiency from an environmental viewpoint is the assessment of the regulation opportunity cost in terms of the desirable production reduction as the difference between a technology that represents either strong or weak disposability of the undesirable products. In other words, the assessment of the efficiency could be measured according to the impact of the environmental regulation, in terms of all those activities to carry out to reach the regulatory pollution standard.

Through the non-parametric frontier model (DEA framework) with the hypothesis of the weak disposability of the undesirable products as a result of the environmental regulation (to maximize the desirable products means fall into some kind of cost to reduce bad by-products), the studies have presented the estimation of efficiency in the presence of the environmental impact via two alternatives (Zofio \& Prieto, 2001; Färe, Grosskopf \& Pasurka, 2007). The main difference between both approaches is the way to measure the efficiency.

First, the directional distance functions (radial), it corresponds to the classical view where the technology of the production function does not change in 
environmental terms in despite of being available relevant information of the negative impacts about the production. These functions imply in a proportional way, increases or decreases of the desirable and undesirable products, where an expansion of the former and a contraction of the latter simultaneously is impossible. There is a positive link between the production levels for both products. The efficiency estimate is given by the maximum increase in the production for the same quantity of the factors. In this approach, the environmental impact of the process is not evaluated. Under the requirement of the weak disposability of the undesirable products and their reduction, based on the compliance with the environmental regulation, the opportunity cost is the decrease of the desirable products because it is not possible to discriminate between both types.

And second, the hyperbolic distance functions (non-radial), where the technology of the production function collect the environmental impact occasioned by the production process. Therefore, there is a negative connection between desirable and undesirable products. The environmental assessment is measured by the trade-off between both types of production. These functions simultaneously represent increases in the desirable and decrease in the undesirable products. The estimation of the efficiency is given by the environmental damage, that is, the maximum increase of the desirable products with the maximum reduction of undesirable. Under the requirement of the weak disposability of the undesirable products and their reduction, based on the compliance with the environmental regulation, there is an opportunity cost for those factors that are employed in "clean" technologies to reduce the undesirable products instead of their use to maximize the production.

Both alternatives are explained in the Figure 7 from the article Zofío \& Prieto (2001). The frontier 0FBCE represents the maximum efficiency from a combination of desirable (p) and undesirable (q) products given a set of factors and a production technology. In this situation there is not an environmental regulation, so there is a strong disposability of the undesirable products. Whereas, the frontier OABCE represents the maximum efficiency under the hypothesis of weak disposability of the undesirable products given the presence of a regulation. In other words, it represents the environmental production frontier where the efficiency estimation involves the assessment of the pollution occasioned by the production. All firms, regardless of whether their production function does not capture the pollution (radial function) or it does it (non-radial function), from any point $(\mathrm{k})$ of their function will aim to reach the environmental frontier ( $\mathrm{k}^{\prime}$ ) to maximize the efficiency of their process. Although, if the public authority sets an ecological standard for the production of undesirable products that imposes its congestion at a certain level $\left(\mathrm{q}_{\mathrm{Q}}\right)$, the firms exhibit two well-differentiated behaviors if the technology of their production function assess environmental impact of their processes. The firm represented by the radial function will move from ( $\left.k^{\prime}\right)$ to $\left(k^{\prime \prime}\right)$ to meet the ecological standard, it decreases the undesirable products but also the desirable (regulation opportunity cost). And the firm with the non-radial function also shifts to ( $\mathrm{k}$ ") beyond the environmental production frontier because the level of congestion of the undesirable product $\left(\mathrm{q}_{\mathrm{Q}}\right)$ can still 
increase more the desirable production at the expense of increasing the consumption of factors employed through the technological innovation to reduce the pollution (the regulation opportunity cost involves the use of factors to decrease the undesirable products rather than being used to increase the desirable ones).

Figure 7. Assessment of the efficiency to the environmental performance via a radial and non-radial function with DEA framework
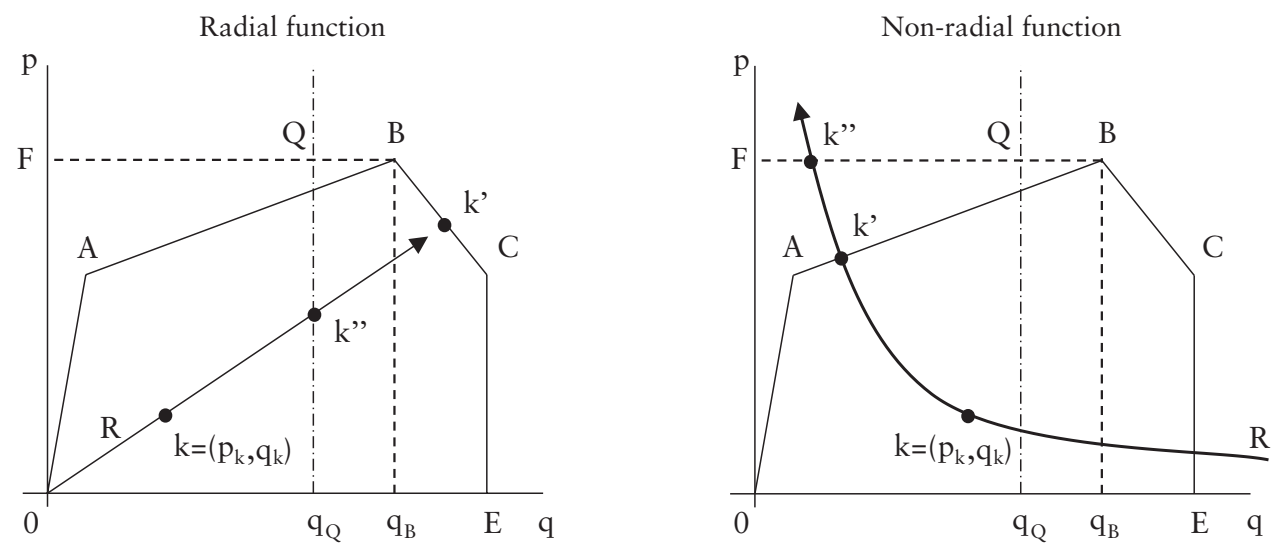

Source: Zofio \& Prieto, 2001.

According to the present graphic description, the radial measures show the efficiency gains at the expense of the environment. These measures are not valid to assess the environmental performance of the production process where there is a desire to eliminate or, at least, reduce the generation of the undesirable products. Thus, the non-radial measures estimate the efficiency of the environmental production by the prevention and the integration of the environment in the production.

The modern studies (Sueyoshi, \& Goto, 2012; and Sueyoshi, \& Goto, 2017) have determined new approaches for the DEA framework where the efficiency for every agent must evaluate the environmental performance through the so-called unified criterion. The unified efficiency consists of the operational efficiency (the measurement is the maximization of the desirable products given a level of factors) and the environmental efficiency (the measurement is the minimization of the undesirable products given a level of factors). Once, the DEA framework is updated to account the undesirable products, it highlights in the non-radial measures two concepts to know how to explain the reduction of the undesirable products.

The same authors suggest the natural and the managerial disposability. The natural disposability indicates the decrease of the factors to decrease the production of the undesirable products, at the same time that increase the desirable products as much as possible. This type of environmental strategy belongs to the conventional view where the environmental regulation negatively influences in the productive 
activity. The managerial disposability indicates the increase of the factors to rise the desirable production at the same time that the undesirable ones is reduced. The pollution of the production will decrease by means of the research to achieve a greater technological innovation and the use of new business management systems. The environmental regulation will provide to the firms new incentives to find new business opportunities and to push up the competition among them. In this way, it will be possible to achieve greater productive prosperity (Porter \& Linde, 1995).

Figure 8. Assessment of the unified efficiency, with DEA framework and non-radial functions, via the natural and managerial disposability to reduce the undesirable products

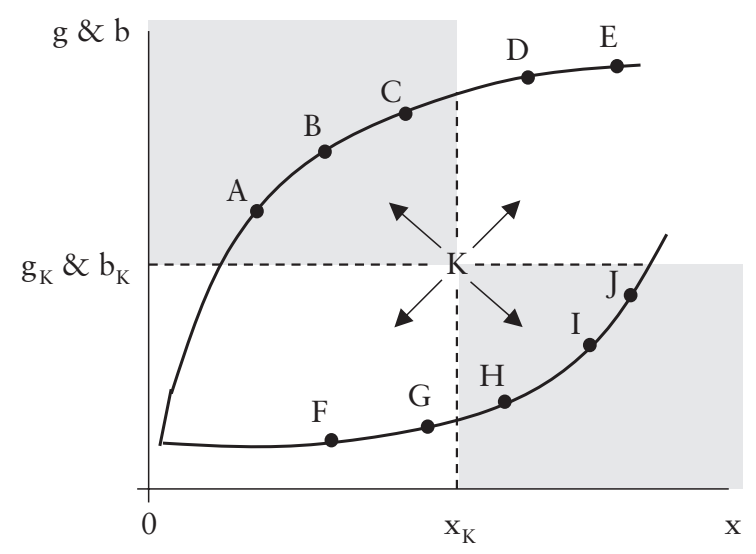

Source: Sueyoshi, T. \& Goto, M., 2017.

The Figure 8 shows the analysis of the efficiency of the environmental assessment for a decision-maker $(\mathrm{K})$ for a given combination of the desirable products $\left(\mathrm{g}_{\mathrm{K}}\right)$, undesirable products $\left(\mathrm{b}_{\mathrm{K}}\right)$ and factors $\left(\mathrm{x}_{\mathrm{K}}\right)$. The model indicates the curve for the efficient frontier of the desirable products above the curve for the efficient frontier of the undesirable products because the first have to aim for the maximization of the desirable production and the second have to aim for the minimization of the undesirable production. Under these requirements, the decision-maker $(\mathrm{K})$ may choose to decrease or increase the consumption of factors in order to reduce the pollution of its activity. If one chooses the first option, it will employ of the natural disposability for it and if one chooses the second option, it will use the managerial disposability to make it.

First of all, if one chooses the natural disposability, the agent is able to move from the current situation $(\mathrm{K})$ towards different possible alternatives according to wish the maximization the desirable products (A, B and $\mathrm{C}$ ) via operational efficiency criterion or, to wish the minimization the undesirable products ( $F$ and $G$ ) via environmental efficiency criterion. The best option given the natural disposability to decrease the undesirable products by means of reducing the use of factors, it will be 
the maximization of the desirable production as much as possible (A, B and C). It will mean a scenario of economic slowdown due to the existence of an environmental regulation that drives the decrease of the pollution. And, in the second place, if one chooses the managerial disposability, likewise the agent is able to move from $(\mathrm{K})$ towards different possible alternatives according to reach a operational criterion (D and $\mathrm{E}$ ) or a environmental criterion ( $\mathrm{H}, \mathrm{I}$ and $\mathrm{J})$. In this case, the best option given the managerial disposability to decrease the undesirable products by means of rising the use of the factors, it will be the minimization of the undesirable production as much as possible ( $\mathrm{H}, \mathrm{I}$ and $\mathrm{J})$. At the same time, it will increase the desirable production thanks to the technological innovation and the business management, the regulation will not be an obstacle to a higher level of sustainable growth.

The final objective of the measurement of the environmental performance in the technical efficiency analysis is to study the best possible behavior in relation to the environmental damage caused in the normal activity of each of the social agents: an individual, a firm, or a state. A behavior that unite an economic vision and ecological efficiency (denominated as eco-efficiency by recent literature). According to the World Business Council for Sustainable Development, the eco-efficiency is reached by the delivery of competitively priced goods and services that satisfy human needs, while progressively reducing environmental impacts and resource intensity throughout the life cycle. The researchers have a special attention in the public sector in order to provide to policy-makers of serious and robust information for the improvement the design of environmental policies in defense of sustainable development approaches fulfilling the commitments to reduce human-generated pollution.

\section{Discussion and conclusions}

It has been carried out a review of the literature on the technical efficiency analysis from an economic perspective to assess the adequacy or no of the behaviors of any agent involved in this process, with special attention to the study of the correct design of the environmental regulation promoted by the Governments.

Thanks to the use of linear programming techniques, the traditional productivity measures have been the basis for the selection of the efficient behaviors for each of the agents involved in a production function where the optimization between the productive factors and the products was the maximum possible. By this way, to set up an envelope of the efficient observations where it estimates the technical efficiency of each agent as a distance function that separate their performance from the frontier, without necessity to available a functional form and a set of price data or granted weights. But it is simply necessary to available quantitative data. This framework is usually denominated Data Envelopment Analysis (DEA).

The exercise of the index numbers has been widely in the literature, since it allows comparing a magnitude in two different situations. In order to analysis the efficiency, the Malmquist productivity index has been the most predominant due to 
the flexibility presented in any situation. The use of the non-parametric techniques and the panel data allows us to decompose the estimation of the technical efficiency change originated between different times periods, on the one hand, a change for technology and, on the other hand, a change for efficiency. In addition, with the variable returns to scale, it would give rise a new component caused for scale.

Nevertheless, the traditional analysis completely ignores the production of the negative externalities in the environment, as well as all the factors dedicated to their elimination. As of this analysis, all the environmental regulations aimed at restricting the productive activities which indirectly result in contamination will have an adverse effect on the efficiency. The theoretical analysis fails because it forgets of the presence of undesirable results (environmental pollution of any kind) since there are usually no prices for them.

The research has developed new approaches to look for those behaviors of the agents, given a production technology, where it is achieved the maximum possible difference between the increase in desirable products and the reduction of negative pollution externalities, in addition to get the maximum possible reduction of all productive factors. There is currently a wide debate without obvious consensus around the direct link between the negative externalities and the level of the production, in the sense of whether it is possible to reduce the pollution with increases or not in the desirable products. The theoretical framework about the introduction of the desirable and undesirable products is well-understood, as the literature examined has showed. However, the how to account for the reduction of the undesirable products, there is still no satisfactory answer (Dyckhoff \& Allen, 2001). Actually, it is hard to think the existence of the polluting products at zero cost for any agent in the economy, both in the presence of regulations and in the absence of them. The bigger environmental social awareness unequivocally requires the weak disposability of the undesirable products. Thus, it is necessary to treat the desirable and undesirable products asymmetrically in terms of the disposability.

As a result of all displayed literature, the environmental regulation should focus its action on a combination of mitigation (with result in the present tense) and adaptation measures (in the future tense) to meet the challenge of the climate change. The development of mitigation measures can now reduce the generation of the undesirable products for the environment and the adaptation measures, through the innovation in technology and in business management, can reduce the generation of these kind of products in the future with the purpose of the implementation of less mitigation measures. Both measures should promote a technical change whose efficiency profits emphasize more environmentally sustainable activities.

Our contribution clarifies that any environmental regulation to maximize the technical efficiency must not limit the productive activity of the agents at any time, in it place, its focus should restrict the generation of the undesirable products as well as the intensity of the factors used. That is, all environmental regulation must try to maximize the production, and minimize the pollution and resources (inverse relationship). The only way to achieve this is through the innovation in the technology 
and the business management. Therefore, our contribution dictates how the environmental regulation should be a combination of measures that promotes the current reduction and the future mitigation of the production impact on nature thanks to the support of an increasingly "cleaner" technology and the boost of a business management that is increasingly aware of its ecological impact among its business targets.

The next steps in the technical efficiency analysis, given the economic and environmental trade-off, can be as Macpherson, Principe \& Smith (2010) points the development of theoretical models that capture temporal dynamics, since many environmental impacts are not shown in the short term but are delayed in time. This development has the limitation that many data sources have inconsistent time scales. Also, another possible improvement of the model would be to investigate the influence of the uncontrollable natural factors (as for example the topography) in the DEA, given this framework is not working well with the random terms. Another way to explore, it would be to create an eco-efficiency frontier with the frontier functions based on non-parametric linear techniques, just as Korhonen \& Luptacik (2004) did it. This frontier was broken down respectively in the analysis of technical (traditional viewpoint) and ecological efficiency (to maximize the ratio between of the desirable and undesirable products).

\section{Declaration of conflicts of interest}

The authors declare that they have no conflicts of interest in relation to the research, authorship and / or publication of this work.

\section{Finance}

The author has not received financial support for the research, authorship and / or publication of this work.

\section{References}

Afriat, S. N., 1972, Efficiency estimation of production functions. International Economic Review, 13 (3), 568-597.

Aigner, D. J., \& Chu, S. F., 1968, On estimating the industry production function. The American Economic Review, 58 (4), 826-839.

Aigner, D. J., Lovell, C. A. K., \& Schmidt, P., 1977, Formulation and estimation of stochastic frontier production function models. Journal of Econometrics, 6, 21-37.

Arkelof, G. A., 1970, The market for "Lemons": Quality uncertainty and the market mechanism. The Quarterly Journal of Economics, 84 (3), 488-500. 
Banker, R. D., \& Morey, R. C., 1985, Efficiency analysis for exogenously fixed inputs and outputs. Operations Research, 34 (4), 513-521.

- 1986, The use of categorical variables in data envelopment analysis. Management Science, 32 (12), 1613-1627.

Banker, R. D., Charnes, A., \& Cooper, W. W., 1984, Some models for estimating of technical and scale inefficiencies in data envelopment analysis. Management Science, 30 (9), 1078-1092. doi:10.1287/mnsc.30.9.1078

Baumol, W. J., 1972, On taxation and the control of externalities. The American Economic Review, 62 (3), 307-322.

Camarero, M., Castillo, J., Picazo-Tadeo, A. J., \& Tamarit, C., 2013, Eco - efficiency and convergence in OECD countries. Environmental and Resource Economics, 55 (1), 87-106. doi:10.1007/s10640-012-9616-9

Caves, D. W., Christensen, L. R., \& Diewert, W. E., 1982, The economic theory of index numbers and the measurement of input, output and productivity. Econometrica, 50 (6), 1393-1414. doi:10.2307/1913388

Charnes, A., Cooper, W. W., \& Rhodes, E., 1978, Measuring the efficiency of decision making units. European Journal of Operational Research, 2 (6), 429-444. doi:10.1016/0377-2217(78)90138-8

- 1981, Evaluating program and managerial efficiency: An application of data envelopment analysis to program follow through. Management Science, 27 (6), 668-697. doi:10.1287/mnsc.27.6.668

Coelli, T. J., \& Rao, D. S. P., 2005, Total factor productivity growth in agriculture: a Malmquist index analysis of 93 countries, 1980-2000. Agricultural Economics, 32 (s1), 115-134. doi:10.1111/j.0169-5150.2004.00018.x

Cook, J., Nuccitelli, D., Green, S., Richardson, M., Winkler, B., Painting, R., Way, R., Jacobs, P., \& Skuce, A., 2013, Quantifying the consensus on anthropogenic global warning in the scientific literature. Environmental Research Letters, 8, 1-7.

Cullinane, K., Ji, P., \& Wang, T., 2005, The relationship between privatization and DEA estimates of efficiency in the container port industry. Journal of Economics and Business, 57 (5), 433-462. doi:10.1016/j.jeconbus.2005.02.007

Du, D., Zhao, X., \& Huang, R., 2017, The impact of climate change on developed economies. Economics Letters, 153, 43-46.

Dyckhoff, H., \& Allen, K., 2001, Measuring ecological efficiency with data envelopment analysis (DEA). European Journal of Operational Research, 132, 312-325.

Emrouznejad, A., Parker, B. R., \& Tavares, G., 2008, Evaluation of research in efficiency and productivity: A survey and analysis of the first 30 years of scholarly literature in DEA. Socio-Economic Planning Sciences, 42 (3), 151-157. doi:10.1016/j.seps.2007.07.002

Färe, R., \& Grosskopf, S., 2003, Nonparametric productivity analysis with undesirable outputs: Comment. American Journal of Agricultural Economics, 85 (4), 1070-1074. doi:10.1111/1467-8276.00510

Färe, R., \& Lovell, C. A. K., 1978, Measuring the technical efficiency of production. Journal of Economic Theory, 19, 150-162. 
Färe, R., Grosskopf, S. \& Pasurka, C., 2007, Environmental production functions and environmental directional distance functions. Energy, 32 (7), 1055-1066. doi:10.1016/j.energy.2006.09.005

Färe, R., Grosskopf, S., Lovell, C. A. K., \& Pasurka, C., 1989, Multilateral productivity comparisons when some outputs are undesirable: A nonparametric approach. The Review of Economics and Statistics, 71 (1), 90. doi:10.2307/1928055

Färe, R., Grosskopf, S., Lovell, C. A. K., \& Yaisawarng, S., 1993, Derivation of shadow prices for undesirable outputs: A distance function approach. The Review of Economics and Statistics, 75 (2), 374-380.

Färe, R., Grosskopf, S., Norris, M., \& Zhang, Z., 1994, Productivity growth, technical progress, and efficiency change in industrialized countries. The American economic review, 84 (1), 66-83. Recuperado de: https://www.jstor.org/stable/ pdf/2117971.pdf

Farrell, M. J., 1957, The measurement of productive efficiency. Journal of the Royal Statistical Society: Series A (General), 120 (3), 253-290. doi:10.2307/2343100

Fried, H. O., Lovell, C. K., Schmidt, S. S., \& Yaisawarng, S., 2002, Accounting for environmental effects and statistical noise in data envelopment analysis. Journal of productivity Analysis, 17 (1-2), 157-174. Recuperado de: https://link.springer. com/content/pdf/10.1023/A:1013548723393.pdf

Fried, H. O., Schmidt, S. S., \& Yaisawarng, S., 1999, Incorporating the operating environment into a nonparametric measure of technical efficiency. Journal of productivity Analysis, 12 (3), 249-267. Recuperado de: https://link.springer.com/ content/pdf/10.1023/A:1007800306752.pdf

Grifell-Tatjé, E., \& Lovell, C. A. K., 1995, A note on the Malmquist productivity index. Economics Letters, 47, 169-175.

Grossman, S. J. \& Stiglitz, J. E., 1980, On the impossibility of informationally efficient markets. The American Economic Review, 70 (3), 393-408.

Grosskopf, S., 1986, The role of the reference technology in measuring productive efficiency. The Economic Journal, 96, 499-513.

Hailu, A., 2003, Nonparametric Productivity Analysis with Undesirable Outputs: Reply. American Journal of Agricultural Economics, 85 (4), 1075-1077. doi:10.1111/1467-8276.00511

Hsiang, S., \& Kopp, R. E., 2018, An economist's guide to climate change science. Journal of Economic Perspectives, 32 (4), 3-32. doi:10.1257/jep.32.4.3

Jeon, B. M., \& Sickles, R. C., 2004, The role of environmental factors in growth accounting. Journal of Applied Econometrics, 19, 567-591.

Koopmans, T. C., 1951, Efficient allocation of resources. Econometrica: Journal of the Econometric Society, 19 (4), 455-465. Recuperado de: https:/www.jstor.org/ stable/pdf/1907467.pdf

Korhonen, P. J., \& Luptacik, M., 2004, Eco-efficiency analysis of power plants: An extension of data envelopment analysis. European Journal of Operational Research, 154 (2), 437-446. doi:10.1016/s0377-2217(03)00180-2 
Kumar, S., 2006, Environmentally sensitive productivity growth: A global analysis using Malmquist-Luenberger index. Ecological Economics, 56 (2), 280-293. doi:10.1016/j.ecolecon.2005.02.004

Kuosmanen, T., 2005, Weak Disposability in Nonparametric Production Analysis with Undesirable Outputs. American Journal of Agricultural Economics, 87 (4), 1077-1082. doi:10.1111/j.1467-8276.2005.00788.x

Leibenstein, H., 1966, Allocative efficiency vs. "X-efficiency". The American Economic Review, 56 (3), 392-415.

Lozano, S., \& Gutiérrez, E., 2008, Non-parametric frontier approach to modelling the relationships among population, GDP, energy consumption and CO2 emissions. Ecological Economics, 66 (4), 687-699. doi:10.1016/j.ecolecon.2007.11.003

Macpherson, A. J., Principe, P. P., \& Smith, E. R., 2010, A directional distance function approach to regional environmental-economic assessments. Ecological Economics, 69 (10), 1918-1925. doi:10.1016/j.ecolecon.2010.04.012

Malmquist, S., 1953, Index numbers and indifference curves. Trabajos de Estadistica, 4 (1), 209-242. https://doi.org/10.1007/bf03006863

Meleddu, M., \& Pulina, M., 2018, The efficiency of the public intervention on the environment: Evidence based on non-parametric and parametric approaches. Journal of Cleaner Production, 183, 744-759. doi:10.1016/j.jclepro.2018.02.134

Meeusen, W., \& Den Broeck, J., 1977, Efficiency estimation from Cobb-Douglas production functions with composed error. International Economic Review, 18 (2), 435-444.

Minsky, H., 1986, Stabilizing an unstable economy. Yale University Press.

Nordhaus, W. D., 1977, Economic growth and climate: the carbon dioxide problem. The American Economic Review, 67 (1), 341-346. Recuperado de: https://www. jstor.org/stable/pdf/1815926

Pittman, R. W., 1983, Multilateral Productivity Comparisons with Undesirable Outputs. The Economic Journal, 93 (372), 883. doi:10.2307/2232753

Porter, M. E., \& Linde, C., 1995, Toward a new conception of the environmentcompetitiveness relationship. Journal of Economic Perspectives, 9 (4), 97-118.

Sanz-Díaz, M. T., Velasco-Morente, F., Yñiguez, R., \& Díaz-Calleja, E., 2017, An analysis of Spain's global and environmental efficiency from a European Union perspective. Energy Policy, 104, 183-193. https://doi.org/10.1016/j. enpol.2017.01.030

Scheel, H., 2001, Undesirable outputs in efficiency valuations. European Journal of Operational Research, 132, 400-410.

Seiford, L. M., \& Thrall, R. M., 1990, The mathematical programming approach to frontier analysis. Journal of Econometrics, 46, 7-38.

Seitz, W. D., 1970, The measurement of efficiency relative to a frontier production function. Journal of Agricultural Economics, 52 (4), 505-511.

Sen, A., 1995, Rationality and social choice. The American Economic Review, 85 (1), 1-24.

Solow, R. M., 1957, Technical change and the aggregate production function. The Review of Economics and Statistics, 39 (3), 312-320. 
Song, M., An, Q., Zhang, W., Wang, Z., \& Wu, J., 2012, Environmental efficiency evaluation based on data envelopment analysis: A review. Renewable and Sustainable Energy Reviews, 16 (7), 4465-4469. doi:10.1016/j.rser.2012.04.052

Stocker, T. F., Qin, D., Plattner, G. K., Tignor, M., Allen, S. K., Boschung, J., \& Midgley, P. M., 2013, Climate change 2013: The physical science basis. Contribution of working group I to the fifth assessment report of the intergovernmental panel on climate change, 1535. doi:10.1017/cbo9781107415324.023

Sueyoshi, T., \& Goto, M., 2012, DEA radial and non-radial models for unified efficiency under natural and managerial disposability: Theoretical extension by strong complementary slackness conditions. Energy Economics, 37, 700-713.

- 2017, Methodological comparison among radial, non-radial and intermediate approaches for DEA environmental assessment. Energy Economics, 67, 439-453.

Tyteca, D., 1996, On the Measurement of the Environmental Performance of Firms- A Literature Review and a Productive Efficiency Perspective. Journal of Environmental Management, 46 (3), 281-308. doi:10.1006/jema.1996.0022

- 1997, Linear programming models for the measurement of environmental performance of firms-concepts and empirical results. Journal of productivity analysis, 8 (2), 183-197. https://link.springer.com/content/pdf/10.1023/A:1013296909029. pdf

Yang, H., \& Pollitt, M., 2009, Incorporating both undesirable outputs and uncontrollable variables into DEA: The performance of Chinese coal-fired power plants. European Journal of Operational Research, 197 (3), 1095-1105. doi:10.1016/j. ejor.2007.12.052

- 2010, The necessity of distinguishing weak and strong disposability among undesirable outputs in DEA: Environmental performance of Chinese coal-fired power plants. Energy Policy, 38 (8), 4440-4444. doi:10.1016/j.enpol.2010.03.075

Zaim, O., 2004, Measuring environmental performance of state manufacturing through changes in pollution intensities: a DEA framework. Ecological Economics, 48 (1), 37-47. doi:10.1016/j.ecolecon.2003.08.003

Zaim, O., \& Taskin, F., 2000, Environmental efficiency in carbon dioxide emissions in the OECD: A non-parametric approach. Journal of Environmental Management, 58, 95-107.

Zofío, J. L., \& Prieto, A. M., 2001, Environmental efficiency and regulatory standards: The case of $\mathrm{CO}_{2}$ emissions from OECD industries. Resource and Energy Economics, 23, 63-83. 


\section{Notes on Contributors}

Name: Jesús Lucindo Blasco

Position: Programa doctorado en Economía

School / Faculty: Facultad de Economía y Empresa

University: Universidad de Zaragoza

Address: Gran Vía 2, 50005 Zaragoza, España

Phone: 976762633

Email:534278@unizar.es

ORCID: 0000-0001-6435-5239

Name: Marisa Feijóo

Position: Profesora Titular de Universidad

School / Faculty: Facultad de Economía y Empresa

University: Universidad de Zaragoza e Instituto Agroalimentario de Aragón (IA2)

Address: Gran Vía 2, 50005 Zaragoza, España

Phone: 976762633

Email:mfeijoo@unizar.es

ORCID: 0000-0001-9819-8649 